\title{
Article \\ Modelling and Optimisation of the Sol-Gel Conditions for Synthesis of Semi-Hexagonal Titania-Based Nano-Catalyst for Esterification Reaction
}

\author{
Hamed Nayebzadeh ${ }^{1, *}$, Abbas Rohani ${ }^{2}$ (D), Aliakbar Sistani ${ }^{3}$, Ali Hassanpour ${ }^{4}$ and Jabbar Gardy ${ }^{4, *(D)}$ \\ 1 Faculty of Material and Chemical Engineering, Esfarayen University of Technology, \\ Esfarayen P.O. Box 96-6189-8195, Iran \\ 2 Department of Biosystems Engineering, Faculty of Agriculture, Ferdowsi University of Mashhad, \\ Mashhad P.O. Box 91-7794-8974, Iran; arohani@um.ac.ir \\ 3 Department of Chemical Engineering, Faculty of Engineering, Ferdowsi University of Mashhad, \\ Mashhad P.O. Box 91-7794-8974, Iran; ali_sistani_2009@yahoo.com \\ 4 School of Chemical and Process Engineering, Faculty of Engineering and Physical Sciences, University of \\ Leeds, Leeds LS2 9JT, UK; a.hassanpour@leeds.ac.uk \\ * Correspondence: h.nayebzadeh@esfarayen.ac.ir (H.N.); j.gardy@leeds.ac.uk (J.G.); \\ Tel.: +98-5837266531 (H.N.); +44-7392333760 (J.G.)
}

check for updates

Citation: Nayebzadeh, H.; Rohani, A.; Sistani, A.; Hassanpour, A.; Gardy, J. Modelling and Optimisation of the Sol-Gel Conditions for Synthesis of Semi-Hexagonal Titania-Based Nano-Catalyst for Esterification Reaction. Catalysts 2022, 12, 239. https://doi.org/10.3390/ catal12020239

Academic Editor: Stéphanie Lambert

Received: 11 January 2022

Accepted: 18 February 2022

Published: 20 February 2022

Publisher's Note: MDPI stays neutral with regard to jurisdictional claims in published maps and institutional affiliations.

Copyright: (C) 2022 by the authors. Licensee MDPI, Basel, Switzerland. This article is an open access article distributed under the terms and conditions of the Creative Commons Attribution (CC BY) license (https:// creativecommons.org/licenses/by/ $4.0 /)$.
Abstract: Design and fabrication of a catalyst with the highest activity can be achieved by optimising the synthesis conditions. In this study, the sol-gel synthesis conditions of citric acid concentration, gelling temperature, complex time, and calcination temperature were studied for the preparation of a novel semi-hexagonal calcium/titania-zirconia nano-catalyst used in the esterification reaction. After synthesis of around 24 samples at various conditions, their activity was tested in the esterification reaction and the results were analysed by multi-layer perceptron (MLP) and support vector machine (SVM) models. Both models predicted the actual data with high coefficients of determination, and indicated that the calcination temperature has the most influence on the activity of the prepared semi-hexagonal calcium/titania-zirconia nano-catalyst for the esterification reaction. Moreover, the genetic algorithm (GA) was utilised for optimising the preparation conditions based on the SVM model, due to its higher generalisation capability for prediction. The prepared nano-catalysts under the optimum conditions of 1.42 acid ratio, gelling temperature of $72{ }^{\circ} \mathrm{C}$, complex time of $2.65 \mathrm{~h}$, and calcination temperature of $487^{\circ} \mathrm{C}$ showed good crystalline structure and metal-metal and metaloxygen cation bonding. Finally, the fabricated catalyst had a high surface area $\left(276.5 \mathrm{~m}^{2} / \mathrm{g}\right)$ with $3.5 \mathrm{~nm}$ pore diameter and almost uniform particle size $(80-110 \mathrm{~nm})$ distribution, leading to a high conversion of $97.6 \%$ in the esterification reaction, with good catalytic stability up to five times.

Keywords: sol-gel method; $\mathrm{TiO}_{2}-\mathrm{ZrO}_{2}$ catalyst; multi-layer perceptron (MLP); support vector machine (SVM); genetic algorithm (GA); esterification

\section{Introduction}

The problems of burning petroleum fuels for production of energy, including air pollution, global warming, climate change, a variety of human diseases, etc. are forcing governments to invest in renewable and biodegradable fuels. It seems that production of alternative and renewable fuels is vital for continuing our life on earth. Since petroleum fuels are mainly consumed in transportation [1,2], compatibility of alternative fuels with diesel engines may be an essential factor for their industrial production [3,4].

Biodiesel, which is usually produced from vegetable oils, can be used as an alternative fuel, as it has similar properties to petroleum fuel, does not necessitate modification of current diesel engines, and is non-toxic and biodegradable [5,6]. Biodiesel is produced via esterification and/or transesterification reactions, in which free fatty acid (FFA) and 
triglyceride (TG), respectively, react with an alcohol (usually methanol) to form ester. To accelerate the reaction, using a catalyst is necessary. Homogenous acid and base catalysts are used for esterification and transesterification reactions, respectively to form biodiesel $[7,8]$.

Due to the drawbacks of homogeneous catalysts for these reactions, such as corrosion, environmentally harmful wastewater, and long and costly separation and neutralisation processes, heterogeneous catalysts have been recently studied [9-11]. However, the reactions using heterogeneous catalysts need more time to be completed compared to those using homogeneous catalysts. Therefore, many researchers have investigated the possibility of synthesising novel heterogeneous catalysts with higher activity [12-14]. In this regard, investigation of bonding several metal cations [15,16], homogeneous cations on the surface of heterogeneous catalyst [17], metal-organic framework catalyst [18], ionic liquid catalysts, heteropoly acids [19], etc. have been examined. In all heterogeneous catalysts, evaluating the conditions of heterogeneous catalyst preparation is crucial.

Heterogeneous catalysts can be fabricated by various methods, such as co-precipitation, impregnation, sol-gel, and hydrothermal, in which different parameters can affect the physicochemical properties, activity, stability, and reusability of fabricated catalysts [20-25]. However, there are some common parameters that must be evaluated in most preparation methods, such as the $\mathrm{pH}$ of the solution, the medium temperature for mixing the precursors, the period for mixing the precursors and the temperature of calcination for the precursor mixture. The calcination temperature, as one of the most important factors, has been deeply studied in the literature [26-28]. For example, $\mathrm{Al}_{2} \mathrm{O}_{3}-\mathrm{ZrO}_{2}$ was fabricated by varying the pre-treatment and calcination temperature ( $\mathrm{RT}, 550$ and $800^{\circ} \mathrm{C}$ ) and it was reported that the calcination had an important effect on the crystalline structure, crystallinity, textural properties, activity, and stability of the sample [29]. The effect of calcination temperature on the catalytic activity of a fabricated $\mathrm{Ni}-\mathrm{Ce}_{0.6} \mathrm{Zr}_{0.4} \mathrm{O}_{2}$ catalyst by co-precipitation method for biodiesel production from oleic acid was assessed [30]. It was reported that the catalyst calcined at $300{ }^{\circ} \mathrm{C}$, exhibiting the highest conversion of oleic acid.

Al-Qaysi et al. [31] synthesised a sulfated $\mathrm{SiO}_{2}-\mathrm{TiO}_{2}$ nano-catalyst via a sol-gel method, and investigated the preparation conditions, including $\mathrm{Si} / \mathrm{Ti}$ ratio, $\mathrm{pH}$ of the preparation medium (nitric acid concentration), and the organic concentration (sulfate group) on the surface of the support. They reported that $\mathrm{Si} / \mathrm{Ti}$ ratio of 0.8 , a nitric acid concentration of $4.0 \mathrm{M}$ and a loading of $1.0 \mathrm{M}$ sulfuric acid solution on the $\mathrm{SiO}_{2}-\mathrm{TiO}_{2}$ surface can provide a catalyst with the highest activity. Sakti La Ore et al. [32] synthesised $\mathrm{SO}_{4} / \mathrm{ZrO}_{2}$ and $\mathrm{Zr} / \mathrm{CaO}$ catalysts via sol-gel and hydrothermal methods along with optimising the calcination temperature as well as the $\mathrm{SO}_{4}$ and $\mathrm{Zr}$ contents on the catalyst support. They reported that $0.5 \mathrm{M} \mathrm{SO}_{4} / \mathrm{ZrO}_{2}$ calcined at $500{ }^{\circ} \mathrm{C}$ converted the highest amount of FFA to biodiesel. Moreover, $15 \% \mathrm{Zr} / \mathrm{CaO}$ calcined at $800{ }^{\circ} \mathrm{C}$ showed the highest basicity and activity in the transesterification reaction. There have been many other similar studies on binary and ternary systems, including $\mathrm{TiO}_{2}-\mathrm{ZrO}_{2}$ [33,34], $\mathrm{CuO}-\mathrm{TiO}_{2}$ [35], $\mathrm{ZrO}_{2}-\mathrm{CaO}$ [36], and $\mathrm{CaO}-\mathrm{TiO}_{2}$ [37], aimed at improving the activity of metal oxide using synergetic properties from oxides.

According to the importance of each parameter to the properties of the final designed catalyst, accurate optimisation would require obtaining maximum catalytic efficiency of esterification and transesterification reactions. The statistical methods, such as response surface method (RSM) [38,39], Taguchi [40], and Box-behnken [41] have rarely been studied in the context of optimising the catalyst preparation conditions. In addition, the limitations of these methods, such as non-applicability of the proposed model outside of the studied range of factors, non-applicability for optimising the problems of highly non-linear multiple objectives, and non-applicability for non-quadratic approximations, artificial neural networks (ANNs) combined with the genetic algorithm (GA) are able to suitably analyse, model and optimise the process parameters [42]. Although a few studies have evaluated the preparation conditions of heterogeneous catalysts via ANN and the process of optimising the parameters using GA $[43,44]$, a lack of study can be observed regarding the preparation conditions of binary or ternary systems of metal oxides. Soleimanzadeh et al. [45] fabri- 
cated $\mathrm{V}_{2} \mathrm{O}_{5} / \mathrm{TiO}_{2}$ nano-catalysts by varying the $\mathrm{V}$ loading, impregnation temperature, and calcination temperature for $\mathrm{NH}_{3}$-selective catalytic reduction of $\mathrm{NOx}$. They firstly used RSM for designing the experiment, then the multilayer perceptron (MLP) neural network was used for assessing the results, and GA was used for optimising the catalyst preparation conditions. Based on the ANN model, they reported that the relative significance of each variable on $\mathrm{NO}$ conversion was calcination temperature, process temperature loading, and impregnation temperature from high to low importance, respectively. However, no study so far has performed the modelling and optimising of heterogeneous catalyst conditions used in the esterification and/or transesterification reactions by using ANN combined with GA.

Therefore, in this study, a ternary system of metal oxides containing $\mathrm{Ca}, \mathrm{Zr}$, and $\mathrm{Ti}$ was synthesised by sol-gel method, in which acid concentration ( $\mathrm{pH}$ of precursor mixture medium), the time for mixing precursors to form a ternary complex system (complex time), the temperature for evaporating the solvent (gelling temperature) and the temperature for forming the final catalyst (calcination temperature) were investigated. The prepared catalysts under various conditions of the sol-gel method were examined in the esterification reaction of oleic acid to form biodiesel. The results of the conversion were assessed by MLP and SVM models. Then, GA was utilised to obtain the optimal conditions of sol-gel method for fabrication of calcium/titania-zirconia catalyst. Moreover, the synthesised catalyst at the optimal conditions suggested by GA was characterised. Finally, the stability of the catalyst was also tested for several uses in the esterification reaction.

\section{Results and Discussion}

\subsection{Assessment of Synthesised Catalysts}

The catalytic activities of synthesised catalysts used in the esterification reaction are listed in Table S1. The non-calcined samples showed the conversion in the range of $50 \%$ to $79 \%$. When the complex time increased to $2 \mathrm{~h}$, the catalytic activity around $10 \%$ improved the connection between the metal cations, due to sufficient duration. Less improvement in activity was observed when further increasing the complex time. The gelling time and the acid ratio showed considerable influence, such that the acid ratio variation from 0.75 to 1.5 caused an increase in the conversion from 62 to 70 , as well as enhancing the gelling temperature from 60 to $80{ }^{\circ} \mathrm{C}$. Higher gelling temperature led to fast evaporation of the solvent and the formation of some clusters, which reduced the catalytic activity. Calcination temperature had a significant impact on the prepared catalyst, this is because of egression of the solvent from the catalyst structure and the formation of metal-metal bonds.

\subsection{Optimisation of Parameters in SVM and MLP Models}

The 50 runs of the esterification reaction were performed by 24 catalysts prepared under different conditions of sol-gel method, and the esterification yield was also studied. The type of training algorithm and the number of neurons in the hidden layer are two important parameters for designing an MLP artificial neural network and its prediction ability. Figure 1 a shows how the training algorithm can be effective. In this Figure, 12 training algorithms based on their RMSE were classified for all data. As the results confirmed, the training algorithm of Levenberg-Marquardt (Trainlm) leads to the minimum RMSE, while the training algorithm of Fletcher-Powell Conjugate Gradient (Traincgf) provides maximum RMSE. Therefore, Trainlm was utilised as a suitable training algorithm for designing an MLP network to model the conversion of oleic acid in the esterification reaction using the mixed metal oxides fabricated at different conditions. The optimum number of neurons in the hidden layer of the MLP neural network must be found. 

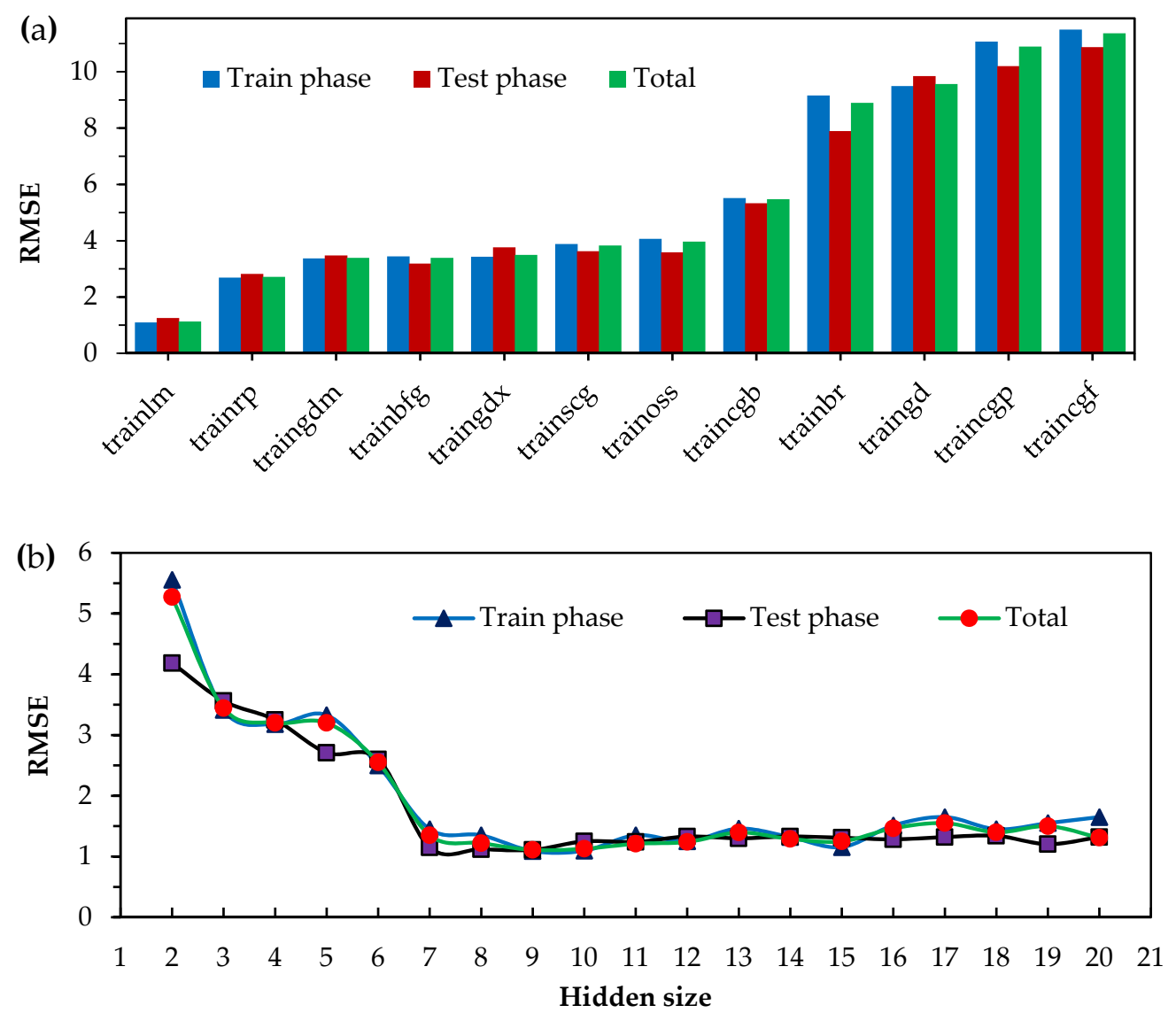

Figure 1. (a) Effect of training algorithm types, and (b) neuron numbers in the hidden layer on RMSE in the three stages of training, test and all data.

Figure $1 \mathrm{~b}$ presents the variation in network RMSE by changing the neurons from 2 to 20 in the hidden layer in the three stages of training, test, and total (all data set). Increasing the neuron numbers to around nine causes RMSE to decrease. However, the RMSE of the test stage increases with an increase in the neurons up to nine, while the RMSE of the training and total stages remains constant. Therefore, the best output was obtained with nine neurons in the hidden layer. A further increase in the neuron layer led to reduce the generalisation capability of the network, and cannot significantly improve the performance of the network. Therefore, the training algorithm of Trainlm, with nine neurons in the hidden layer of the MLP network, was used for modelling the activity of the catalysts in an esterification reaction.

In SVM design, the type of kernel function can have an important role. RMSE values in the three stages of training, test and both stages for the four kernel functions of linear (Poly1), second-order (Poly2), third-order (Poly3), and radial bias function (RBF) are illustrated in Figure 2. It was found that the RBF function exhibits the best correlation for modelling the response (conversion). The worst result was mainly owing to the linear function, due to the nonlinear relationship between the four independent variables and the conversion. Therefore, the RBF kernel function was utilised for designing the SVM model. 


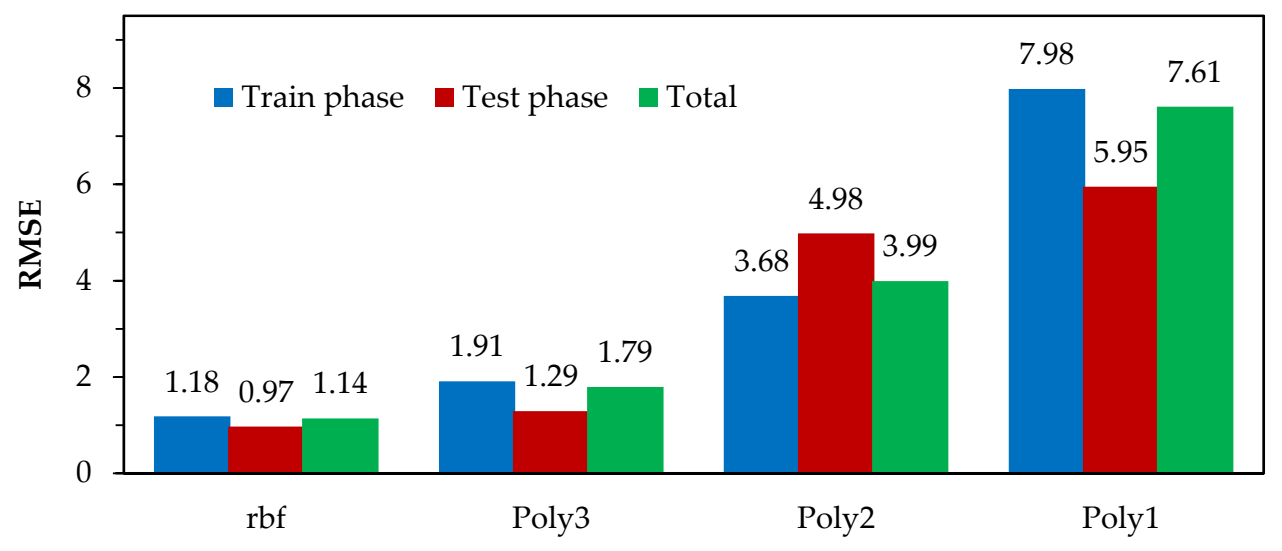

Figure 2. RMSE values for SVM model in three stages of learning, test, training, and total, using kernel functions of linear (Poly1), second-order (Poly2), third-order (Poly3), and base radial (RBF) for modelling the catalytic activity of the sample in the esterification reaction.

\subsection{Assessment of SVM and MLP Models}

After choosing the best effective parameters of the MLP and SVM models, the prediction ability of these models was compared. Figure 3 shows the results of predicted vs. experimental data for the catalytic activity of the fabricated catalysts in the esterification reaction via MLP and SVM. The obtained regression coefficient $\left(R^{2}\right)$ in the two steps of training and test was higher than $98 \%$ for both models, which indicates good correlation between actual and predicted data. Therefore, both the MLP and SVM models can meaningfully predict the data in the test step.
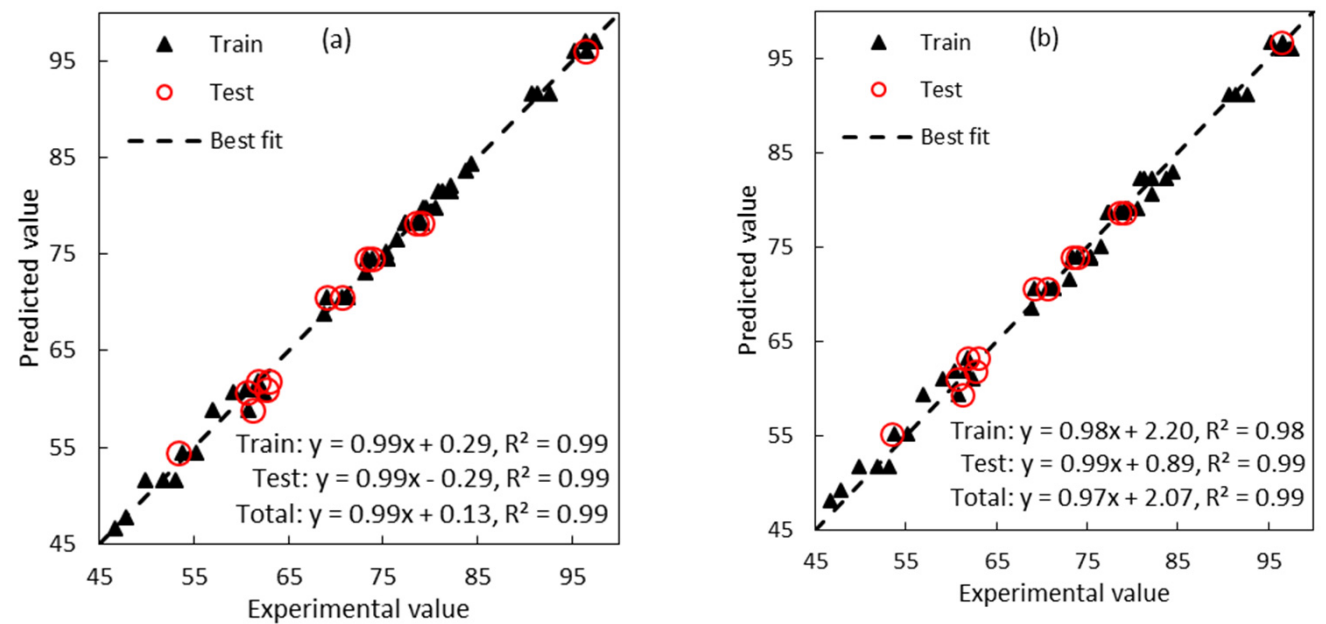

Figure 3. Predicted vs. actual data obtained from (a) MLP and (b) SVM models.

For better evaluating the models, various sizes of training and test sets were used and the results are summarised in Table 1. According to the data listed in this Table, RMSE values increase continuously with the decrease in the size of the training set for both the MLP and SVM models. However, the SVM model shows better prediction in the test step than the MLP model. In addition, the RMSE value for the SVM model for a training set size lower than $40 \%$ receives to 3 (the maximum value). Therefore, the SVM model had more generalisation capability for prediction, because the SVM model could exhibit acceptable error in the test step with a smaller training data set. 
Table 1. The results of generalisation capability MLP and SVM models based on RMSE.

\begin{tabular}{cccccccc}
\hline \multicolumn{2}{c}{ Divide Data Set } & & MLP & & & SVM & Tht \\
\hline Train Ratio & Test Ratio & Train & Test & Total & Train & Total \\
\hline 80 & 20 & 1.09 & 1.11 & 1.11 & 1.18 & 0.97 & 1.14 \\
60 & 40 & 1.59 & 4.78 & 3.26 & 2.10 & 1.57 & 3.34 \\
40 & 60 & 2.34 & 6.37 & 5.16 & 2.10 & 2.85 & 4.80 \\
20 & 80 & 3.61 & 7.31 & 6.72 & 2.05 & 51 & \\
\hline
\end{tabular}

\subsection{Sensitivity Analysis}

The sensitivity analysis was utilised for assessing the importance of four independent variables (acid ratio, gelling temperature, complex time, and calcination temperature) in estimating and influencing response (catalytic activity of the catalysts). The results of the sensitivity analysis of independent variables on dependent variables based on RMSE in the three steps of training, test, and total for the MLP and SVM models are shown in Table 2. In this analysis, each variable with the most negative influence on the RMSE of a model was eliminated. The results show that calcination temperature, gelling temperature, complex time, and acid ratio have the greatest to least effect, respectively, on the catalyst activity. Elimination of calcination temperature can increase the prediction error to five times.

Table 2. Sensitivity analysis of MLP and SVM models based on RMSE value.

\begin{tabular}{ccccccc}
\hline & & MLP & & & \multicolumn{2}{c}{ SVM } \\
\cline { 2 - 7 } & Train & Test & Total & Train & Test & Total \\
\hline All independent variables & 1.09 & 1.11 & 1.11 & 1.18 & 0.97 & 1.14 \\
All excluding gelling temp & 4.74 & 3.84 & 4.57 & 5.15 & 3.11 & 4.81 \\
All excluding complex time & 3.54 & 4.06 & 3.65 & 3.87 & 4.66 & 4.04 \\
All excluding acid ratio & 3.19 & 3.89 & 3.35 & 2.99 & 3.84 & 3.18 \\
All excluding calcination temp & 9.28 & 6.42 & 8.77 & 7.12 & 4.59 & 6.67 \\
\hline
\end{tabular}

\subsection{Assessment of Independent Variable Interaction}

The effect of independent variable interaction on the response (catalyst activity) was investigated by three-dimensional response surface plots, as shown in Figure 4 . The effect of the interaction of gelling temperature and complex time on the conversion of oleic acid in the esterification reaction, with acid ratio and calcination temperature both constant at 1.5 and $150{ }^{\circ} \mathrm{C}$, respectively, (Figure 4a) shows that increasing the gelling time to $75^{\circ} \mathrm{C}$ causes an increase in the catalytic activity in the esterification reaction. It was also reported that the gelling temperature controls the rate of water evaporation from the precursor's mixture [46]. Less evaporation causes trapping of the water molecules into the metal oxide structure, and inhibits the bonding of metal cations. On the other hand, the metal cation bonds cannot form by the evaporation of water molecules at high temperature. Therefore, a slight reduction in yield can be observed by raising the gelling temperature. At the optimum gelling temperature, increasing the complex time leads to a sharp increase in the yield of the reaction. Formation of metal cation-O-metal cation bonds is a slow process that requires sufficient time to achieve a suitable structure [47]. Therefore, complex time has a significant role in the formation of the desirable structure and activity of the catalyst. 

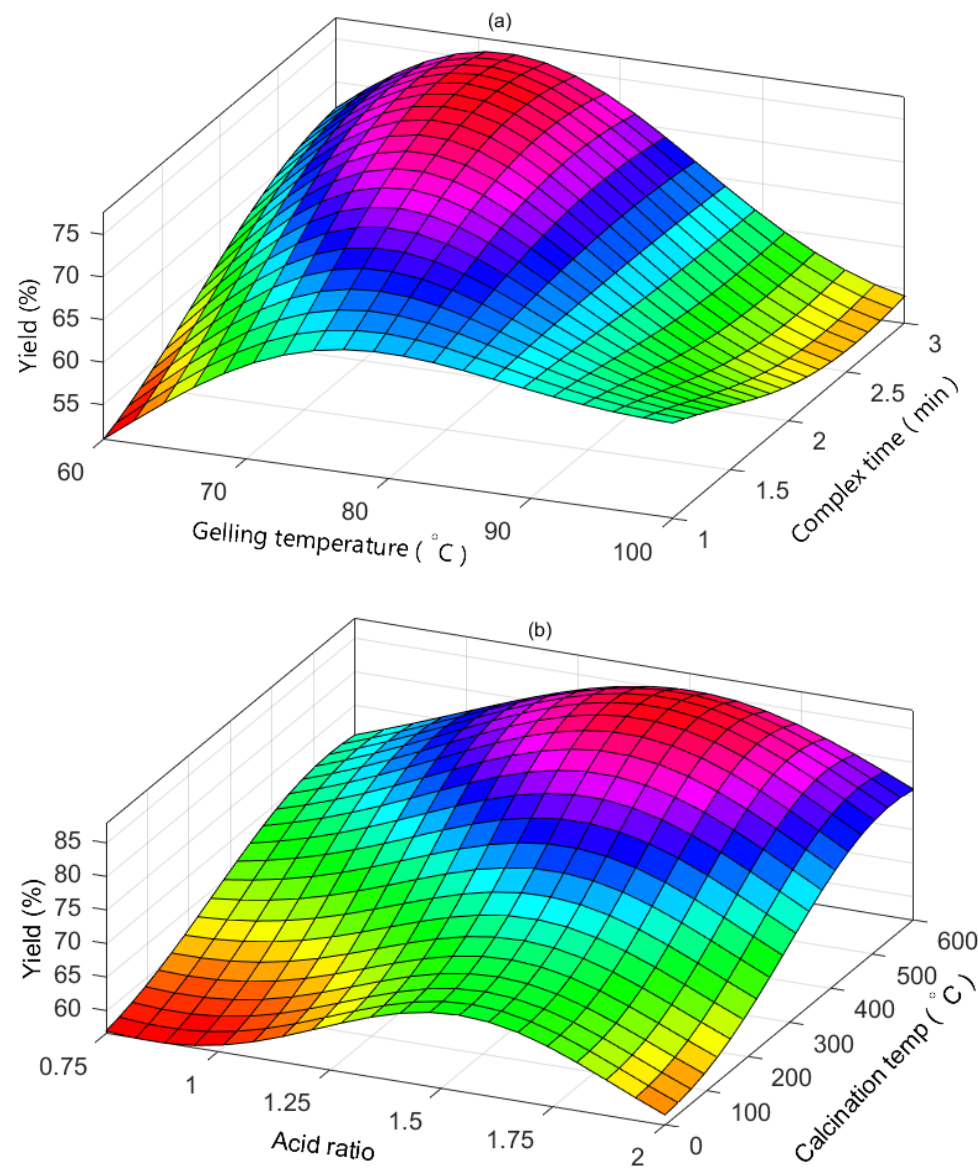

Figure 4. Three-dimensional plots of the effects of (a) gelling temperature and complex time, (b) calcination temperature and acid ratio interactions on the catalytic activity of the catalyst in the esterification reaction (yield).

Figure $4 \mathrm{~b}$ shows the effect of calcination temperature and acid ratio interaction on the catalytic activity of the catalysts in the esterification reaction while keeping gelling temperature and complex time constant at $75^{\circ} \mathrm{C}$ and $1.5 \mathrm{~h}$, respectively. The acid ratio has a direct relationship with the $\mathrm{pH}$ of the synthesised final powder. Therefore, the $\mathrm{pH}$ of the medium must be optimised due to the negative influence of highly acidic medium on the growth of crystals, which could affect the crystalline size and the activity of the catalyst [48]. An acid ratio in the range of $1.25-1.75$ seems to be appropriate for obtaining a catalyst with high catalytic activity in the esterification reaction.

Calcination temperature has a major role in the egression of unwanted components (nitrate, water, etc.) from mixed metal oxide to obtain a final fabricated catalyst with a desirable structure. However, high temperature can also have a negative influence, due to increasing the cost of catalyst preparation as well as sintering the sample, which increases the crystalline size of the final catalyst $[28,49]$. Therefore, $400-500{ }^{\circ} \mathrm{C}$ can be considered the optimum calcination temperature range.

\subsection{Optimisation of Catalyst Synthesis Conditions Using Genetic Algorithm}

The SVM model as a fitness function in the genetic algorithm was used for achieving the highest catalytic activity in the esterification reaction by adjusting the four independent variables to the best levels. The GA started by solving the 50 randomised solutions within the range of studied independent variables. The optimum solution was obtained using stochastic uniform as the selection method, uniform mutation, and heuristic crossover, in which the solution converges to the best level of each independent variable. The converging 
plot of GA is depicted in Figure 5, showing that the GA converged after 50 generations of solution.

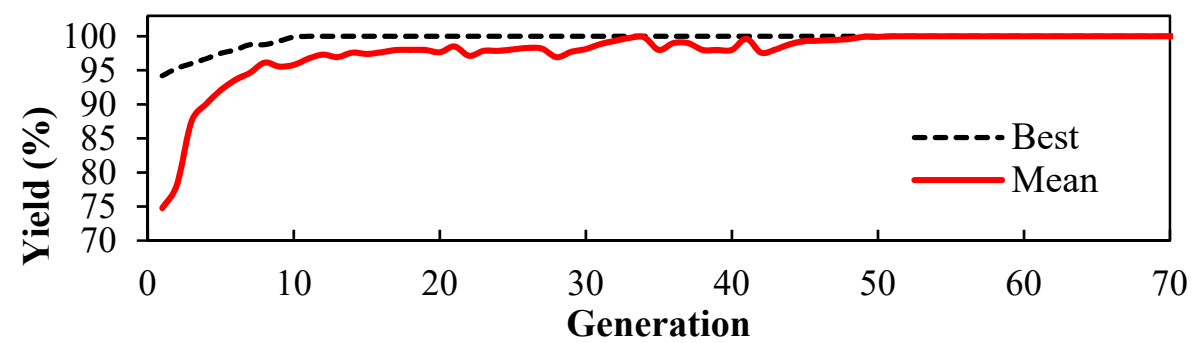

Figure 5. Converging plot of genetic algorithm for optimising preparation conditions of catalysts via sol-gel method using SVM model.

The results of GA optimisation are listed in Table 3. According to the best solution suggested by GA under the SVM model, the highest yield $(100 \%)$ can be obtained by adjusting the acid ratio, gelling temperature, complex time, and calcination temperature at $1.42,72{ }^{\circ} \mathrm{C}, 2.65 \mathrm{~h}$, and $487^{\circ} \mathrm{C}$, respectively. Comparing the result of GA optimisation with the best result of actual (experimental) data shows that the proposed solution via genetic algorithm can be achieved by varying the preparation conditions.

Table 3. The suggested optimum conditions with genetic algorithm for catalyst preparation via sol-gel method and experiment data.

\begin{tabular}{cccccc}
\hline & $\begin{array}{c}\text { Acid Ratio } \\
(\mathbf{m o l} / \mathbf{m o l})\end{array}$ & $\begin{array}{c}\text { Gelling } \\
\text { Temp. }\left({ }^{\circ} \mathbf{C}\right)\end{array}$ & $\begin{array}{c}\text { Complex } \\
\text { Time (h) }\end{array}$ & $\begin{array}{c}\text { Calcination } \\
\text { Temp. }\left({ }^{\circ} \mathbf{C}\right)\end{array}$ & $\begin{array}{c}\text { Yield } \\
(\mathbf{\%})\end{array}$ \\
\hline Experimental data & 1.5 & 70 & 3 & 400 & 97.1 \\
First solution of GA & 1.42 & 72 & 2.65 & 487 & 100 \\
Second solution of GA & 1.40 & 75 & 2.50 & 500 & 99.8 \\
\hline
\end{tabular}

\subsection{Structural Assessment of Optimum Catalyst}

The calcium/titania-zirconia was synthesised under the optimum conditions obtained by GA (acid ratio of 1.42 , gelling temperature of $72{ }^{\circ} \mathrm{C}$, complex time of $2.65 \mathrm{~h}$, and calcination temperature of $487^{\circ} \mathrm{C}$ ) and characterised by X-ray powder diffraction (XRD), texture analyser, Fourier transform infrared spectroscopy (FTIR), and thermogravimetric analysis (TGA) - differential thermal analysis (DTA) analyses, and the results are presented in Figure 6. The XRD pattern (Figure 6a) shows the anatase phase of $\mathrm{TiO}_{2}(\mathrm{JCPDS}$ No. 71-1166) as major phase. Moreover, zirconia structure in monoclinic phase (JCPDS No. 83-0942) with less intensity can be detected. This may be related to good dispersion of $\mathrm{Zr}$ cation on the titania lattice [50-52]. Moreover, the diffraction peaks of $\mathrm{CaO}$ can be also observed, which is matched by JCPDS No. 74-1226. 


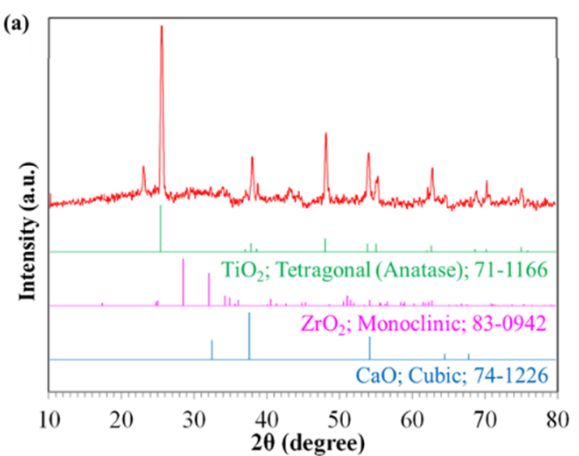

(b)

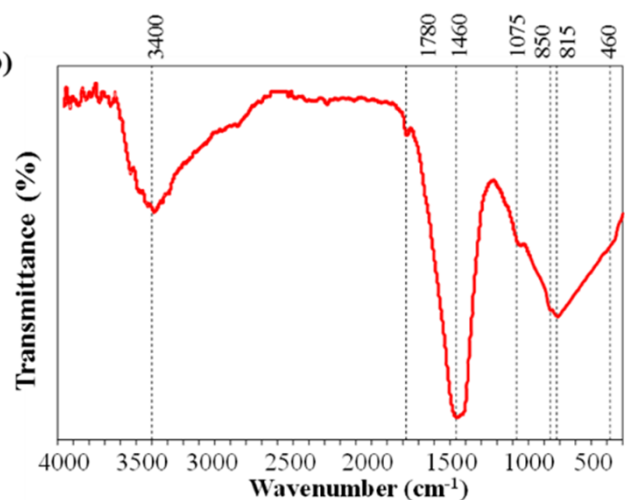

(c)

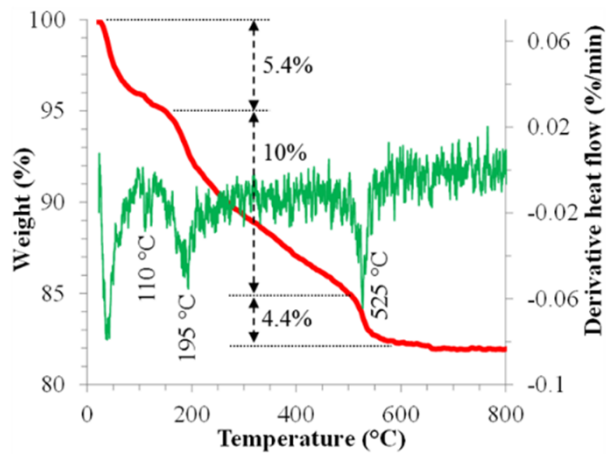

Figure 6. (a) XRD profile (b) FTIR spectrum, (c) TGA-DTA curves and (d) BET-BJH profile of calcium/titania-zirconia catalyst.

The FTIR spectrum of the calcium/titania-zirconia nano-catalyst (Figure $6 \mathrm{~b}$ ) shows a weak peak at $460 \mathrm{~cm}^{-1}$ and a broad peak in the range of 500-900 $\mathrm{cm}^{-1}$, which are respectively corresponded to the $\mathrm{Ca}-\mathrm{O}[49]$ and $\mathrm{X}-\mathrm{O}-\mathrm{X}(\mathrm{X}=\mathrm{Zr}$ or Ti) bands $[53,54]$. The sharp peak at $1460 \mathrm{~cm}^{-1}$ is related to the $\mathrm{X}-\mathrm{O}-\mathrm{H}$ bands [55]. The hydrophilic property of the synthesised catalyst is confirmed by a sharp broad band at $3400 \mathrm{~cm}^{-1}$, which is assigned to the $\mathrm{O}-\mathrm{H}$ stretching vibration of water molecules [56]. The bands at $1075 \mathrm{~cm}^{-1}$ and $1780 \mathrm{~cm}^{-1}$ may be represent carbon and oxygen bonds from adsorbed $\mathrm{CO}_{2}$ in air on the surface of the catalyst, especially by Ca species [57].

The TGA profile of the calcium/titania-zirconia nano-catalyst (Figure 6c) exhibit three weight loss regions which also confirms by DTA profile at 110,195 and $525^{\circ} \mathrm{C}$ peaks. The physically adsorbed water on the surface of the catalyst was evaporated in the first region (DTA peak at $110^{\circ} \mathrm{C}$ ) with weight loss of 5.4\% [58]. The second weight loss was mainly owing to the loss of structural water. As discussed in the FTIR section, the catalyst sample had strong hydrophilic properties, confirming a large amount of weight loss $(10 \%)$ in the second region $\left(100-450{ }^{\circ} \mathrm{C}\right)$. Moreover, egression of carbon groups, such as $\mathrm{CO}_{2}$, may have occurred in this region [57]. In the last region, from 450 to $600{ }^{\circ} \mathrm{C}, 4 \%$ weight loss was detected, due to decomposition of organic (if any) groups and diffusion of $\mathrm{Zr} / \mathrm{Ca}$ cations into the titania lattice [59]. However, the weight loss in the third section was low, and this confirms a good calcination process in the sample for forming a calcium/titania-zirconia nano-composite.

The textural properties of calcium/titania-zirconia were measured by BrunauerEmmett-Teller (BET) method, and surface area, total pore volume, and mean pore size were obtained, measuring $276.5 \mathrm{~m}^{2} / \mathrm{g}, 0.777 \mathrm{~cm}^{3} / \mathrm{g}$ and $3.6 \mathrm{~nm}$, respectively. The nano-catalyst showed a large surface area and pore volume, which caused better interaction between the reactants. Moreover, the mean pore size (greater than $3 \mathrm{~nm}$ ) was sufficient for the diffusion of large molecules of oleic acid into the pores, and for maximal availability of the reactants to the external and internal surface areas [60]. The $\mathrm{N}_{2}$ adsorption-desorption plot is also shown in (Figure 6d), and relates to Type IV and H1 hysteresis loop which are typically 
associated with capillary condensation within cylindrical mesopores [61]. The pore size distribution profile (inset in Figure 6d) can clarify the porous structure of the synthesized material, in which the pore sizes were greater than $2 \mathrm{~nm}$.

The Field emission-scanning electron microscopy (FE-SEM) images and surface particle size distribution of the calcium/titania-zirconia nano-catalyst are shown in Figure 7. Semi-hexagonal particles can be seen that are partially formed in three dimensions. According to the SEM result, the detected particle size was in the range of $60-160 \mathrm{~nm}$ with an average particle size of $91 \mathrm{~nm}$.
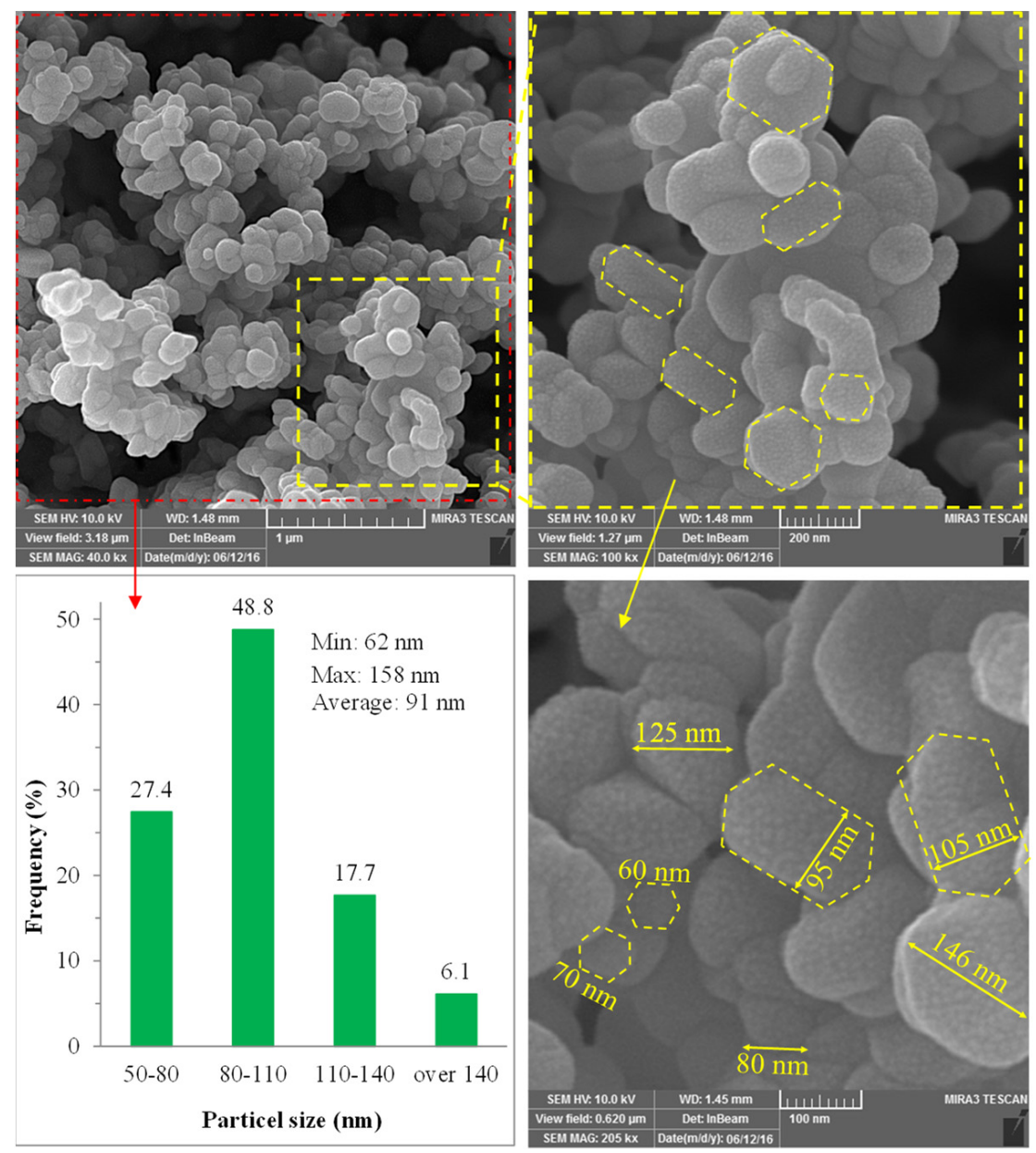

Figure 7. FE-SEM images and surface particle size distribution of calcium/titania-zirconia catalyst synthesised via sol-gel method at the optimum conditions suggested by GA.

Transmission electron microscopy (TEM) images of calcium/titania-zirconia nanocatalyst, as shown in Figure 8, exhibit some particles with a hexagonal shape and others with a semi-hexagonal shape, which may also be transformed into a hexagonal shape with a change in the sol-gel synthesis conditions or with assessment of other effective parameters. 


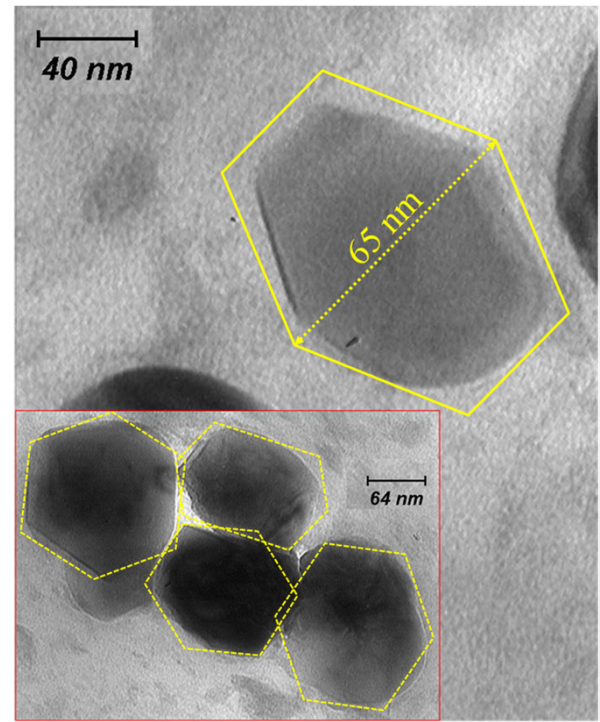

Figure 8. TEM image of calcium/titania-zirconia catalyst synthesised via sol-gel method at the optimum conditions suggested by GA.

\subsection{Reusability Assessment of the Optimum Nano-Catalyst}

The stability of a heterogeneous catalyst is an important factor for assessing its industrial application. The calcium/titania-zirconia nano-catalyst was separated after each reaction and washed with methanol-hexane with a ratio of 1:1 vol.\% to remove any remaining products and reactants from the surface and pores of the catalyst. Afterwards, the recycled catalyst was oven-dried and re-used in the next run. The results for catalyst reusability are presented in Figure 9, and it can be seen that the catalyst shows good catalyst stability in the esterification reaction. The reduction in activity after 5 cycles can be explained by the reaction between calcium oxide as base catalyst and oleic acid as free fatty acid, which possibly forms a very small portion of fatty acid salt (soap) that causes partial poisoning of the catalyst [56].

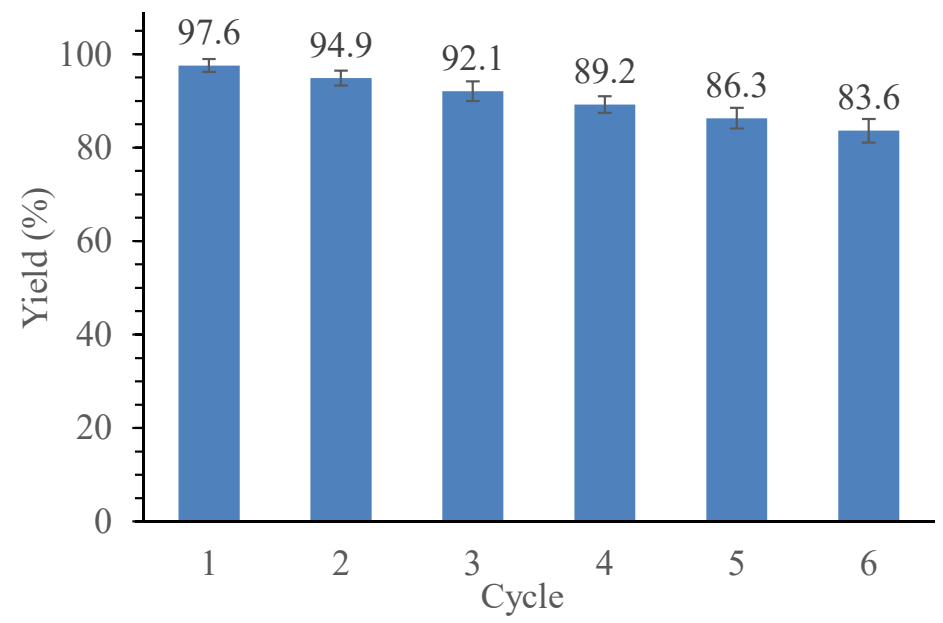

Figure 9. Reusability of calcium/titania-zirconia catalyst in the esterification reaction.

\section{Materials and Methods}

\subsection{Catalyst Preparation}

The calcium/titania-zirconia catalyst was synthesised in a one step via sol-gel method. The process consists of dispersing $\mathrm{TiO}_{2}$ powder in $14 \mathrm{M}$ nitric acid solution and adding calcium nitrate $\left(\mathrm{Ca}\left(\mathrm{NO}_{3}\right)_{2} \cdot 4 \mathrm{H}_{2} \mathrm{O} ; 99 \%\right.$ purity, Merck, Kenilworth, NJ, USA) and zirconium nitrate $\left(\mathrm{ZrO}\left(\mathrm{NO}_{3}\right)_{2} \cdot \mathrm{xH}_{2} \mathrm{O} ; 98 \%\right.$, Sigma Aldrich, Burlington, MA, USA). The precursor 
amount was adjusted so that the final molar ratio of Ca:Ti:Zr was 2:1:1 wt\%. Then, citric acid was added to adjust the $\mathrm{pH}$ of the medium and make a complex from three metal cations, and the mixture was transferred into a three-neck, round-bottomed flask for refluxing with continuous stirring. After the desirable time, the mixture was aged and oven-dried at $110{ }^{\circ} \mathrm{C}$ overnight, and then calcined at various temperatures. The variables and their levels are summarised in Table 4 . A total of 24 catalysts were prepared by varying the sol-gel process conditions.

Table 4. Variables of sol-gel method and their levels.

\begin{tabular}{ccccccc}
\hline Variables & Unit & \multicolumn{5}{c}{ Levels } \\
Acid ratio & mol/mol & 0.75 & 1 & 1.5 & 2 \\
Complex time & $\mathrm{h}$ & 1 & 1.5 & 2 & 3 & 100 \\
Gelling temperature & ${ }^{\circ} \mathrm{C}$ & 60 & 70 & 80 & 400 & 500 \\
Calcination temperature & ${ }^{\circ} \mathrm{C}$ & 0 & 200 & 300 & 400 \\
\hline
\end{tabular}

\subsection{Catalyst Characterisation}

The calcium/titania-zirconia catalyst fabricated at the optimal conditions suggested by GA was characterised using XRD, FTIR, TGA, BET surface analyser, FE-SEM and TEM. The XRD analysis was performed on UNISANTIS/XMD 300 in the range of $10-80^{\circ}$ and steps $0.05^{\circ}$ [62]. The FTIR spectrum was collected on a SHIMADZU 4300 (Japan) spectrometer between 400 and $4000 \mathrm{~cm}^{-1}$ with a resolution of $4 \mathrm{~cm}^{-1}$. TGA was carried out on an Evolution STA (SETARAM, France) under air gas at a heating rate of $20^{\circ} \mathrm{C} / \mathrm{min}$ from 50 to $800^{\circ} \mathrm{C}$. Surface area and porosity analyses were performed by $\mathrm{N}_{2}$ adsorption-desorption at $-196^{\circ} \mathrm{C}$ using Belsorp mini II (BelJapan) system after the catalyst was degassed at $120^{\circ} \mathrm{C}$ in vacuum overnight. The morphology and particle size distribution of the prepared catalyst were examined by FE-SEM using MIRA3 FEG-SEM (TESCAN, Czech Republic) operated at $10 \mathrm{kV}$ and TEM on LEO 912AB TEM operated at $200 \mathrm{kV}$ [63].

\subsection{Catalyst Testing}

The activity of the catalysts was examined in the esterification reaction of oleic acid with methanol at a temperature of $150{ }^{\circ} \mathrm{C}$ for $4 \mathrm{~h}$. The reaction was performed in an $80 \mathrm{~mL}$ stainless steel reactor by charging with $20 \mathrm{~g}$ oleic acid, $26 \mathrm{~mL}$ methanol and $0.6 \mathrm{~g}$ of synthesised catalyst [49]. After completing the reaction, the reaction mixture was centrifuged to separate the ester layer from the catalyst and by-product (water). The ester layer (biodiesel) was heated at $80{ }^{\circ} \mathrm{C}$ for $2 \mathrm{~h}$ to evaporate any remaining excess methanol and traces of water/moisture, and the conversion was obtained by measuring the reduction of the acid index of the oleic acid to its ester using the titration method with an alcoholic $\mathrm{KOH}(0.1 \mathrm{M})$ solution [64].

$$
\text { Conversion }(\%)=\frac{\mathrm{AV}_{\text {Oleic acid }}-\mathrm{AV}_{\text {Methyl ester }}}{\mathrm{AV_{ \text {Oleicacid } }}} \times 100
$$

where $\mathrm{AV}$ is the acid value (index).

\subsection{Multi-Layer Perceptron (MLP) Model}

The MLP structure used for estimating the esterification yield as dependent variables and independent variables of acid ratio, gelling temperature, complex time, and calcination temperature is depicted in Figure 10. The MLP neural network consists of three layers: an input layer, a hidden layer, and an output layer [42]. In our study, an input layer has four neurons, each of which represents an independent variable. The hidden layer contains a few neurons, the number of which affects the prediction error of the esterification yield. According to the universal approximation theorem, the MLP model can predict any continuous function with any desired accuracy by having only one hidden layer and suitable amounts of neurons [65]. MLP utilises a supervised learning technique, in which 
the neurons of the input layer with the hidden layer and hidden layer with the output layer with the weight matrix. Adjusting the weights and finding their optimum values are the main approach for making a correlation between inputs and output [66]. For this purpose, the training algorithm was used for adjusting the weights between neurons.

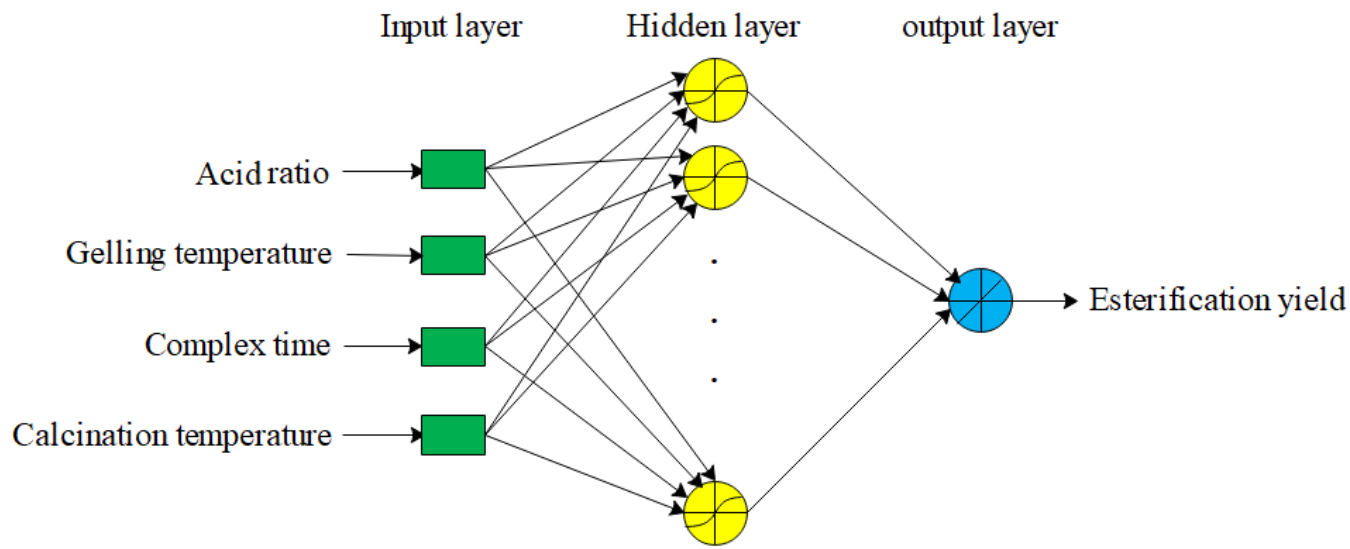

Figure 10. Neural network of MLP for estimation of yield.

In this study, 12 learning algorithms were used [67], as listed in Table 5. The analyses of neural networks were performed by the MATLAB software package (version 9.6.0.1072779 with neural network toolbox, MathWorks, Inc., Natick, MA, USA).

Table 5. Learning algorithm for weight optimisation within neurons in MLP.

\begin{tabular}{cc}
\hline Function & Algorithm \\
\hline trainlm & Levenberg-Marquardt \\
trainrp & Resilient Backpropagation \\
traingdm & Gradient Descent with Momentum \\
trainbfg & BFGS Quasi-Newton \\
traingdx & Variable Learning Rate Gradient Descent \\
trainscg & Scaled Conjugate Gradient \\
trainoss & One Step Secant \\
traincgb & Conjugate Gradient with Powell/Beale Restarts \\
trainbr & Bayesian Regularisation \\
traingd & Gradient Descent \\
traincgp & Polak-Ribiére Conjugate Gradient \\
traincgf & Fletcher-Powell Conjugate Gradient \\
\hline
\end{tabular}

\subsection{Support Vector Machine (SVM) Model}

The SVM model as a nonparametric method was introduced by Vladimir Vapnik [68]. Generalisation ability is one of the advantages of the SVM model, which is why this model is also used for estimation of yield based on presented independent variables. The SVM model works based on least square, and the kernel function has the most impact on the designing and prediction errors of the SVM model. In this study, four kinds of kernel function (polynomial degree 1 (Poly1), polynomial degree 2 (Poly2), polynomial degree 3 (Poly3), and radial basis function (RBF)) were utilised [69]. The SVM structure used is illustrated in Figure 11. In the training step, quadratic programming was used for obtaining the coefficients of model 1. 


$$
\begin{gathered}
L(\alpha)=\frac{1}{2} \sum_{i=1}^{N} \sum_{j=1}^{N}\left(\alpha_{i}-\alpha_{i}^{*}\right)\left(\alpha_{j}-\alpha_{j}^{*}\right) G\left(x_{i}, x_{j}\right)+\varepsilon \sum_{i=1}^{N}\left(\alpha_{i}+\alpha_{i}^{*}\right)-\sum_{i=1}^{N} y_{i}\left(\alpha_{i}-\alpha_{i}^{*}\right) \\
\text { Subject to : } \\
\sum_{i=1}^{N}\left(\alpha_{n}-\alpha_{n}^{*}\right)=0 \\
\forall n: 0 \leq \alpha_{n} \leq C \\
\forall n: 0 \leq \alpha_{n}^{*} \leq C
\end{gathered}
$$

where $C$ is the box constraint, $\varepsilon$ is the epsilon margin, $G\left(x_{i}, x_{j}\right)$ is the kernel function, $L$ is the loss function, and $\alpha, \alpha^{*}$ is the nonnegative multiplier.

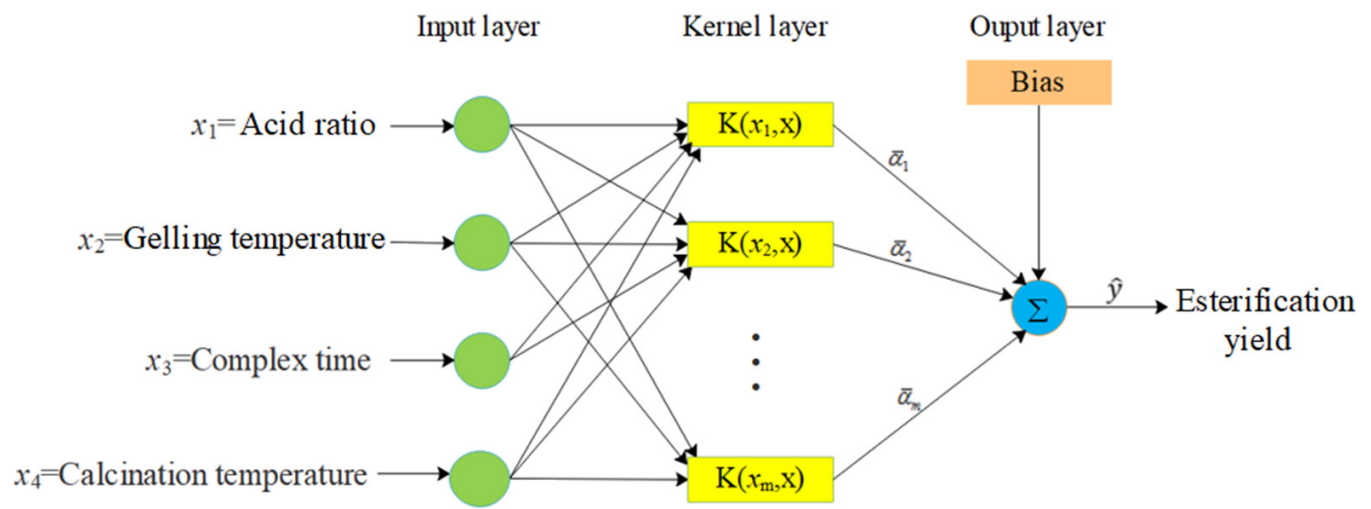

Figure 11. Neural network of SVM for estimation of yield.

\subsection{Genetic Algorithm (GA) for Yield Optimisation}

GA provides a primary population of candidate solutions in the range of studied variables $[44,45]$. In this study, the primary population was 50 , in which the ranges of the independent variables of acid ratio, gelling temperature, complex time, and calcination temperature, were respectively set at [0.75-2], [60-100 $\left.{ }^{\circ} \mathrm{C}\right],[1-3 \mathrm{~h}]$, and $\left[0-600{ }^{\circ} \mathrm{C}\right]$. The schematic of GA structure is shown in Figure 12. The fitness function was used for the fitness of each solution that the SVM or MLP models could be utilised for based on their accuracy analysis results. Moreover, stochastic uniform was used as the selection method for choosing the parents in the next generation. Then, scattered crossover was performed to combine two parents and produce the next generation. Gaussian method was also used for mutation which some of individuals in the population would be randomly changed during the mutation process [70].

\subsection{MLP and SVM Assessment Criteria}

Coefficient of determination $\left(R^{2}\right)$ and root mean square error (RMSE) were utilised for obtaining the design parameters of the MLP and SVM models and evaluating their prediction accuracy. The best results were obtained when $R^{2}$ and RMSE were near to 1 and 0 , respectively, leading to predicted yields $\left(y_{p}\right)$ that were close to actual yields $\left(y_{e}\right)$.

$$
\begin{gathered}
\operatorname{RMSE}=\sqrt{\frac{\sum_{i=1}^{n}\left(y_{e}-y_{p}\right)^{2}}{n}} \\
R^{2}=\left[\frac{\sum_{i=1}^{n}\left(y_{e i}-\overline{y_{e}}\right)\left(y_{p i}-\overline{y_{p}}\right)}{\left.\overline{\sum_{i=1}^{n}\left(y_{e i}-\overline{y_{e}}\right) \sum_{i=1}^{n}\left(y_{p i}-\overline{y_{p}}\right)}\right]^{2}}\right.
\end{gathered}
$$




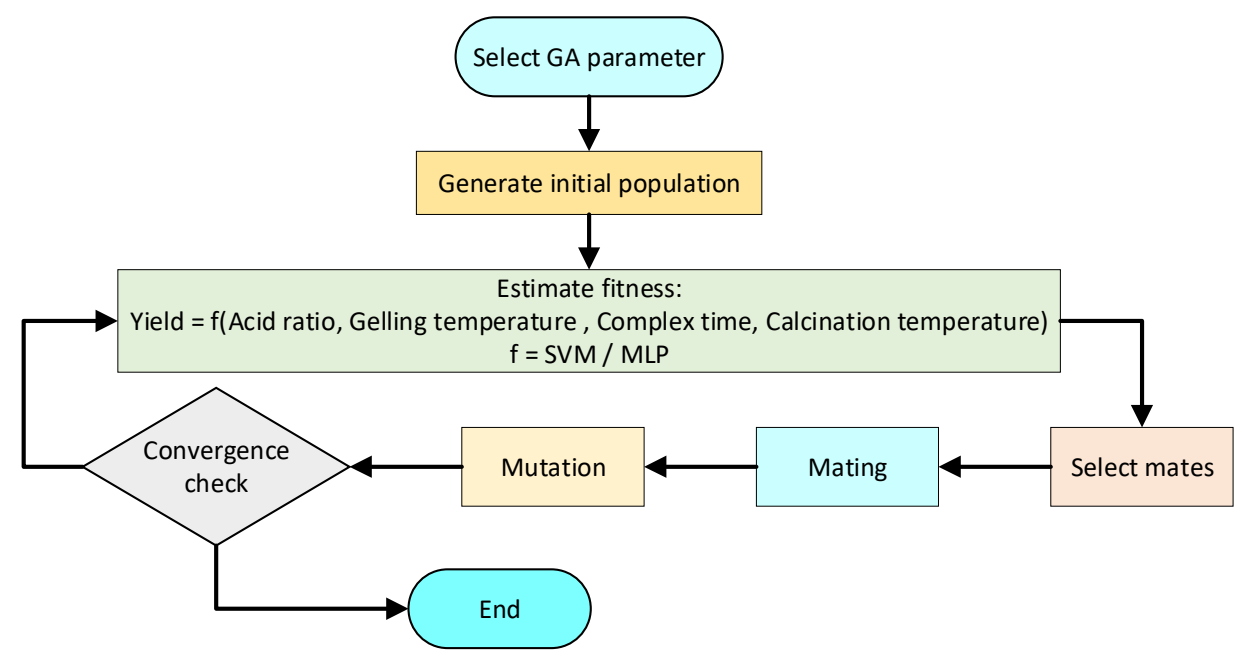

Figure 12. Genetic algorithm structure for maximising the yield.

\section{Conclusions}

The titania-zirconia binary system, as one of the attractive mixed metal oxides, is utilised for many chemical reactions, such as esterification and transesterification reactions for production of biofuel. Calcium oxide is modified the support of catalyst to enhance its activity when the sol-gel method is used. However, the conditions of the preparation method have significant influence on the physical-chemical properties and activity of the final catalyst sample. Therefore, citric acid ratio, gelling temperature, complex time, and calcination temperature, as some of effective variables were assessed in this study. The genetic algorithm combined by the SVM and MLP models was utilised to predict the actual results. The equation presented by the MLP and SVM models showed appropriate correlation with actual results in regard to the optimum conditions suggested for acid ratio, gelling temperature, complex time, and calcination temperature, being $1.42,72{ }^{\circ} \mathrm{C}, 2.65 \mathrm{~h}$, and $487^{\circ} \mathrm{C}$, respectively. The catalyst sample synthesised under the optimal conditions had anatase $\mathrm{TiO}_{2}$ as the main phase of the catalyst, good thermal stability with high surface area, and semi-hexagonal morphology, with average particle size around $90 \mathrm{~nm}$. Moreover, the catalyst presented high activity of $97.6 \pm 1.4 \%$, and stability of five consecutive reaction cycles with $100 \%$ oleic acid.

Supplementary Materials: The following are available online at https:/ /www.mdpi.com/article/10 .3390 / catal12020239/s1, Table S1: The level of depend variables used for synthesis the calcium/titaniazirconia catalyst and their activity in the esterification reaction.

Author Contributions: Conceptualisation, H.N. and A.R.; methodology, A.S.; modelling, A.R.; formal analysis, H.N. \& A.S.; investigation, H.N., A.S., A.R., J.G. and A.H.; writing-original draft preparation, A.S.; writing - review and editing, H.N., A.S., A.R., J.G. and A.H.; project administration, H.N. All authors have read and agreed to the published version of the manuscript.

Funding: J.G. acknowledges financial support from the MDPI publisher for the APC funding.

Data Availability Statement: Not applicable.

Conflicts of Interest: The authors declare no conflict of interest.

Sample Availability: Samples of the synthesised $\mathrm{CaO} / \mathrm{SiO}_{2}-\mathrm{TiO}_{2}$ catalysts are available from the authors. 


\section{Nomenclature}

\begin{tabular}{ll} 
MLP & Multi-layer perceptron \\
SVM & Support vector machine \\
GA & Genetic algorithm \\
FFA & Free fatty acid \\
TG & Triglyceride \\
ANN & Artificial neural network \\
XRD & X-ray powder diffraction \\
FTIR & Fourier-transform infrared spectroscopy \\
TGA & Thermogravimetric analysis \\
BET & Brunauer-Emmett-Teller \\
FESEM & Field Emission Scanning Electron Microscopy \\
TEM & Transmission electron microscopy \\
R & Coefficient of determination \\
RMSE & Root mean square error \\
Trainlm & Training algorithm of Levenberg-Marquardt \\
Traincgf & Training algorithm of Fletcher-Powell Conjugate Gradient \\
Poly1 & Kernel functions of linear \\
Poly2 & Second-order function \\
Poly3 & Third-order function \\
RBF & Radial bias function \\
& \\
\hline
\end{tabular}

\section{References}

1. Younis, K.A.; Gardy, J.L.; Barzinji, K.S. Production and characterization of biodiesel from locally sourced sesame seed oil, used cooking oil and other commercial vegetable oils in Erbil-Iraqi Kurdistan. J. Am. J. Appl. Chem. 2014, 2, 105-111.

2. Lowe, B.; Gardy, J.; Hassanpour, A. The role of sulfated materials for biodiesel production from cheap raw materials. Catalysts 2022, 12, 223. [CrossRef]

3. Abomohra, A.E.-F.; Elsayed, M.; Esakkimuthu, S.; El-Sheekh, M.; Hanelt, D. Potential of fat, oil and grease (FOG) for biodiesel production: A critical review on the recent progress and future perspectives. Prog. Energy Combust. Sci. 2020, 81, 100868. [CrossRef]

4. Gardy, J.L.I.A. Biodiesel Production from Used Cooking Oil Using Novel Solid Acid Catalysts. Ph.D. Thessis, University of Leeds, Leeds, UK, 2017.

5. Mazubert, A.; Poux, M.; Aubin, J. Intensified processes for FAME production from waste cooking oil: A technological review. Chem. Eng. J. 2013, 233, 201-223. [CrossRef]

6. Chozhavendhan, S.; Vijay Pradhap Singh, M.; Fransila, B.; Praveen Kumar, R.; Karthiga Devi, G. A review on influencing parameters of biodiesel production and purification processes. Curr. Res. Green Sustain. Chem. 2020, 1-2, 1-6. [CrossRef]

7. Singh, D.; Sharma, D.; Soni, S.L.; Sharma, S.; Kumar Sharma, P.; Jhalani, A. A review on feedstocks, production processes, and yield for different generations of biodiesel. Fuel 2020, 262, 116553. [CrossRef]

8. Gardy, J.; Rehan, M.; Hassanpour, A.; Lai, X.; Nizami, A.-S. Advances in nano-catalysts based biodiesel production from non-food feedstocks. J. Environ. Manag. 2019, 249, 109316. [CrossRef]

9. Chua, S.Y.; Periasamy, L.A.P.; Goh, C.M.H.; Tan, Y.H.; Mubarak, N.M.; Kansedo, J.; Khalid, M.; Walvekar, R.; Abdullah, E.C. Biodiesel synthesis using natural solid catalyst derived from biomass waste-A review. J. Ind. Eng. Chem. 2020, 81, 41-60. [CrossRef]

10. Mansir, N.; Taufiq-Yap, Y.H.; Rashid, U.; Lokman, I.M. Investigation of heterogeneous solid acid catalyst performance on low grade feedstocks for biodiesel production: A review. Energy Convers. Manag. 2017, 141, 171-182. [CrossRef]

11. Gardy, J.; Osatiashtiani, A.; Céspedes, O.; Hassanpour, A.; Lai, X.; Lee, A.F.; Wilson, K.; Rehan, M. A magnetically separable $\mathrm{SO}_{4} / \mathrm{Fe}-\mathrm{Al}-\mathrm{TiO}_{2}$ solid acid catalyst for biodiesel production from waste cooking oil. J. Appl. Catal. B Environ. 2018, 234, 268-278. [CrossRef]

12. Mardhiah, H.H.; Ong, H.C.; Masjuki, H.H.; Lim, S.; Lee, H.V. A review on latest developments and future prospects of heterogeneous catalyst in biodiesel production from non-edible oils. Renew. Sustain. Energy Rev. 2017, 67, 1225-1236. [CrossRef]

13. Gardy, J.; Nourafkan, E.; Osatiashtiani, A.; Lee, A.F.; Wilson, K.; Hassanpour, A.; Lai, X. A core-shell SO 4 /Mg-Al-Fe 3 O 4 catalyst for biodiesel production. J. Appl. Catal. B Environ. 2019, 259, 118093. [CrossRef]

14. Lowe, B.; Gardy, J.; Wu, K.; Hassanpour, A. Mixed metal oxide catalysts. In Bio-Diesel Production: Feedstocks, Catalysts and Technologies; Rokhum, S.L., Halder, G., Assabumrun, S., Ngaosuwan., K., Eds.; John Wiley \& Sons Ltd.: Hoboken, NJ, USA, 2021; pp. 143-166.

15. Kesserwan, F.; Ahmad, M.N.; Khalil, M.; El-Rassy, H. Hybrid $\mathrm{CaO} / \mathrm{Al}_{2} \mathrm{O}_{3}$ aerogel as heterogeneous catalyst for biodiesel production. Chem. Eng. J. 2020, 385, 123834. [CrossRef] 
16. Al-Qaysi, K.; Nayebzadeh, H.; Saghatoleslami, N.; Gardy, J. Effect of the loading of di-and tri-valent metal cations on the performance of sulfated silica-titania nano-catalyst in the esterification reaction. J. Nanostruct. 2021, 11, $221-235$.

17. Chen, C.; Cai, L.; Zhang, L.; Fu, W.; Hong, Y.; Gao, X.; Jiang, Y.; Li, L.; Yan, X.; Wu, G. Transesterification of rice bran oil to biodiesel using mesoporous NaBeta zeolite-supported molybdenum catalyst: Experimental and kinetic studies. Chem. Eng. J. 2020, 382, 122839. [CrossRef]

18. Li, H.; Wang, Y.; Ma, X.; Wu, Z.; Cui, P.; Lu, W.; Liu, F.; Chu, H.; Wang, Y. A novel magnetic CaO-based catalyst synthesis and characterization: Enhancing the catalytic activity and stability of $\mathrm{CaO}$ for biodiesel production. Chem. Eng. J. 2020, $391,123549$. [CrossRef]

19. Zhang, H.; Tian, F.; Xu, L.; Peng, R.; Li, Y.; Deng, J. Batch and continuous esterification for the direct synthesis of high qualified biodiesel from waste cooking oils (WCO) with Amberlyst-15/Poly (vinyl alcohol) membrane as a bifunctional catalyst. Chem. Eng. J. 2020, 388, 124214. [CrossRef]

20. Gupta, J.; Agarwal, M.; Dalai, A.K. An overview on the recent advancements of sustainable heterogeneous catalysts and prominent continuous reactor for biodiesel production. J. Ind. Eng. Chem. 2020, 88, 58-77. [CrossRef]

21. Ravi, A.; Gurunathan, B.; Rajendiran, N.; Varjani, S.; Gnansounou, E.; Pandey, A.; You, S.; Raman, J.K.; Ramanujam, P. Contemporary approaches towards augmentation of distinctive heterogeneous catalyst for sustainable biodiesel production. Environ. Technol. Innov. 2020, 19, 100906. [CrossRef]

22. Gardy, J.; Hassanpour, A.; Lai, X.; Ahmed, M.H.; Rehan, M. Biodiesel production from used cooking oil using a novel surface functionalised $\mathrm{TiO}_{2}$ nano-catalyst. J. Appl. Catal. B Environ. 2017, 207, 297-310. [CrossRef]

23. Gardy, J.; Hassanpour, A.; Lai, X.; Ahmed, M.H. Synthesis of $\mathrm{Ti}\left(\mathrm{SO}_{4}\right) \mathrm{O}$ solid acid nano-catalyst and its application for biodiesel production from used cooking oil. J. Appl. Catal. A Gen. 2016, 527, 81-95. [CrossRef]

24. Lowe, B.; Ahmad, A.; Gardy, J.; Hassanpour, A. Nanomaterials used in biorefineries: Types, properties, and synthesis methods. In Nanotechnology for Biorefinery; Ingle, A.P., Ed.; Elsevier: Amsterdam, The Netherlands, 2022.

25. Enesca, A.; Isac, L.; Duta, A. Charge carriers injection in tandem semiconductors for dyes mineralization. J. Appl. Catal. B Environ. 2015, 162, 352-363. [CrossRef]

26. Nayebzadeh, H.; Saghatoleslami, N.; Rahmani Vahid, B.; Maskooki, A. Effect of calcination temperature on catalytic activity of synthesis $\mathrm{SrO} / \mathrm{S}-\mathrm{ZrO}_{2}$ by solvent-free method in esterification of oleic acid. Chem. Biochem. Eng. Q. 2013, 23, $267-273$.

27. Vahid, B.R.; Saghatoleslami, N.; Nayebzadeh, H.; Maskooki, A. Preparation of nano-size Al-promoted sulfated zirconia and the impact of calcination temperature on its catalytic activity. Chem. Biochem. Eng. Q. 2012, 26, 71-77.

28. Pinto, B.F.; Garcia, M.A.S.; Costa, J.C.S.; de Moura, C.V.R.; de Abreu, W.C.; de Moura, E.M. Effect of calcination temperature on the application of molybdenum trioxide acid catalyst: Screening of substrates for biodiesel production. Fuel 2019, 239, 290-296. [CrossRef]

29. Al-Fatesh, A.S.; Abu-Dahrieh, J.K.; Atia, H.; Armbruster, U.; Ibrahim, A.A.; Khan, W.U.; Abasaeed, A.E.; Fakeeha, A.H. Effect of pre-treatment and calcination temperature on $\mathrm{Al}_{2} \mathrm{O} 3-\mathrm{ZrO}_{2}$ supported Ni-Co catalysts for dry reforming of methane. Int. J. Hydrog. Energy 2019, 44, 21546-21558. [CrossRef]

30. Jeon, K.-W.; Shim, J.-O.; Jang, W.-J.; Lee, D.-W.; Na, H.-S.; Kim, H.-M.; Lee, Y.-L.; Yoo, S.-Y.; Roh, H.-S.; Jeon, B.-H.; et al. Effect of calcination temperature on the association between free $\mathrm{NiO}$ species and catalytic activity of $\mathrm{Ni}-\mathrm{Ce}_{0.6} \mathrm{Zr}_{0.4} \mathrm{O}_{2}$ deoxygenation catalysts for biodiesel production. Renew. Energy 2019, 131, 144-151. [CrossRef]

31. Al-Qaysi, K.; Nayebzadeh, H.; Saghatoleslami, N. Comprehensive Study on the Effect of Preparation Conditions on the Activity of Sulfated Silica-Titania for Green Biofuel Production. J. Inorg. Organomet. Polym. Mater. 2020, in press. [CrossRef]

32. Sakti La Ore, M.; Wijaya, K.; Trisunaryanti, W.; Saputri, W.D.; Heraldy, E.; Yuwana, N.W.; Hariani, P.L.; Budiman, A.; Sudiono, S. The synthesis of $\mathrm{SO}_{4} / \mathrm{ZrO}_{2}$ and $\mathrm{Zr} / \mathrm{CaO}$ catalysts via hydrothermal treatment and their application for conversion of low-grade coconut oil into biodiesel. J. Environ. Chem. Eng. 2020, 8, 104205. [CrossRef]

33. Kitajima, H.; Higashino, Y.; Matsuda, S.; Zhong, H.; Watanabe, M.; Aida, T.M.; Smith, R.L. Isomerization of glucose at hydrothermal condition with $\mathrm{TiO}_{2}, \mathrm{ZrO}_{2}, \mathrm{CaO}$-doped $\mathrm{ZrO}_{2}$ or $\mathrm{TiO}_{2}$-doped $\mathrm{ZrO}_{2}$. Catal. Today 2016, 274, 67-72. [CrossRef]

34. Ibrahim, M.M.; Mahmoud, H.R.; El-Molla, S.A. Influence of support on physicochemical properties of $\mathrm{ZrO}_{2}$ based solid acid heterogeneous catalysts for biodiesel production. Catal. Commun. 2019, 122, 10-15. [CrossRef]

35. De, A.; Boxi, S.S. Application of $\mathrm{Cu}$ impregnated $\mathrm{TiO}_{2}$ as a heterogeneous nanocatalyst for the production of biodiesel from palm oil. Fuel 2020, 265, 117019. [CrossRef]

36. Salinas, D.; Guerrero, S.; Campos, C.H.; Bustamante, T.M.; Pecchi, G. The Effect of the $\mathrm{ZrO}_{2}$ Loading in $\mathrm{SiO}_{2} @ \mathrm{ZrO}_{2}-\mathrm{CaO}$ Catalysts for Transesterification Reaction. Materials 2020, 13, 221. [CrossRef] [PubMed]

37. Mohamad, M.; Ngadi, N.; Wong, S.; Yahya, N.Y.; Inuwa, I.M.; Lani, N.S. Synthesis and Characterization of CaO-TiO 2 for Transesterification of Vegetable Palm Oil. Int. J. Eng. 2018, 31, 1326-1333.

38. Nayebzadeh, H.; Saghatoleslami, N.; Tabasizadeh, M. Optimization of the activity of KOH/calcium aluminate nanocatalyst for biodiesel production using response surface methodology. J. Taiwan Inst. Chem. Eng. 2016, 68, 379-386. [CrossRef]

39. Mirzaei, M.; Sabbaghi, S.; Zerafat, M.M. Photo-catalytic degradation of formaldehyde using nitrogen-doped TiO ${ }_{2}$ nanophotocatalyst: Statistical design with response surface methodology (RSM). Can. J. Chem. Eng. 2018, 96, 2544-2552. [CrossRef]

40. Naghibi, S.; Faghihi Sani, M.A.; Hosseini, H.R.M. Application of the statistical Taguchi method to optimize TiO 2 nanoparticles synthesis by the hydrothermal assisted sol-gel technique. Ceram. Int. 2014, 40, 4193-4201. [CrossRef] 
41. Mohammad, A.-T.; Abdulhameed, A.S.; Jawad, A.H. Box-Behnken design to optimize the synthesis of new crosslinked chitosanglyoxal/ $\mathrm{TiO}_{2}$ nanocomposite: Methyl orange adsorption and mechanism studies. Int. J. Biol. Macromol. 2019, 129, 98-109. [CrossRef]

42. Azadi, S.; Karimi-Jashni, A.; Javadpour, S. Modeling and optimization of photocatalytic treatment of landfill leachate using tungsten-doped $\mathrm{TiO}_{2}$ nano-photocatalysts: Application of artificial neural network and genetic algorithm. Process. Saf. Environ. Prot. 2018, 117, 267-277. [CrossRef]

43. Pereira, S.R.M.; Clerc, F.; Farrusseng, D.; van der Waal, J.C.; Maschmeyer, T.; Mirodatos, C. Effect of the Genetic Algorithm Parameters on the Optimisation of Heterogeneous Catalysts. QSAR Comb. Sci. 2005, 24, 45-57. [CrossRef]

44. Kim, S.; Sohn, K.-S.; Pyo, M. Genetic Algorithm-Assisted Optimization of Nanoporous $\mathrm{TiO}_{2}$ for Low-Temperature Processable Photoanodes of Dye-Sensitized Solar Cells. ACS Comb. Sci. 2011, 13, 101-106. [CrossRef] [PubMed]

45. Soleimanzadeh, H.; Niaei, A.; Salari, D.; Tarjomannejad, A.; Penner, S.; Grünbacher, M.; Hosseini, S.A.; Mousavi, S.M. Modeling and optimization of $\mathrm{V}_{2} \mathrm{O}_{5} / \mathrm{TiO}_{2}$ nanocatalysts for NH3-Selective catalytic reduction (SCR) of NOx by RSM and ANN techniques. J. Environ. Manag. 2019, 238, 360-367. [CrossRef] [PubMed]

46. Hatte, Q.; Dubos, P.-A.; Guitter, N.; Richard-Plouet, M.; Casari, P. Influence of relative humidity and temperature on the sol-gel transition of a siloxane surface treatment. J. Sol.-Gel Sci. Technol. 2019, 90, 230-240. [CrossRef]

47. Zhang, J.-M.; Zhai, S.-R.; Zhai, B.; An, Q.-D.; Tian, G. Crucial factors affecting the physicochemical properties of sol-gel produced $\mathrm{Fe}_{3} \mathrm{O}_{4} @ \mathrm{SiO}_{2}-\mathrm{NH}_{2}$ core-shell nanomaterials. J. Sol.-Gel Sci. Technol. 2012, 64, 347-357. [CrossRef]

48. Cheng, L.-j.; Liu, Z.; Yuan, S.-1.; Hu, X.; Zhang, B.; Jiang, Y. Preparation of Ag-Mn $/ \gamma-\mathrm{Al}_{2} \mathrm{O}_{3}-\mathrm{TiO}_{2}$ catalysts by complexationimpregnation process with citric acid and its application in propane catalytic combustion. J. Fuel Chem. Technol. 2019, 47, 1379-1385. [CrossRef]

49. Sistani, A.; Saghatoleslami, N.; Nayebzadeh, H. Influence of calcination temperature on the activity of mesoporous $\mathrm{CaO} / \mathrm{TiO}_{2}-$ $\mathrm{ZrO}_{2}$ catalyst in the esterification reaction. J. Nanostructure Chem. 2018, 8, 321-331. [CrossRef]

50. Silahua-Pavón, A.A.; Espinosa-González, C.G.; Ortiz-Chi, F.; Pacheco-Sosa, J.G.; Pérez-Vidal, H.; Arévalo-Pérez, J.C.; Godavarthi, S.; Torres-Torres, J.G. Production of 5-HMF from glucose using $\mathrm{TiO}_{2}-\mathrm{ZrO}_{2}$ catalysts: Effect of the sol-gel synthesis additive. Catal. Commun. 2019, 129, 105723. [CrossRef]

51. Fan, M.; Si, Z.; Sun, W.; Zhang, P. Sulfonated $\mathrm{ZrO}_{2}-\mathrm{TiO}_{2}$ nanorods as efficient solid acid catalysts for heterogeneous esterification of palmitic acid. Fuel 2019, 252, 254-261. [CrossRef]

52. Li, K.-T.; Wang, C.-K.; Wang, I.; Wang, C.-M. Esterification of lactic acid over $\mathrm{TiO}_{2}-\mathrm{ZrO}_{2}$ catalysts. Appl. Catal. A Gen. 2011, 392, 180-183. [CrossRef]

53. Nayebzadeh, H.; Haghighi, M.; Saghatoleslami, N.; Alaei, S.; Yousefi, S. Texture/phase evolution during plasma treatment of microwave-combustion synthesized $\mathrm{KOH} / \mathrm{Ca}_{12} \mathrm{Al}_{14} \mathrm{O}_{33}-\mathrm{C}$ nanocatalyst for reusability enhancement in conversion of canola oil to biodiesel. Renew. Energy 2019, 139, 28-39. [CrossRef]

54. Kazemifard, S.; Nayebzadeh, H.; Saghatoleslami, N.; Safakish, E. Assessment the activity of magnetic $\mathrm{KOH}_{2} \mathrm{Fe}_{3} \mathrm{O}_{4} @ \mathrm{Al}_{2} \mathrm{O}_{3}$ core-shell nanocatalyst in transesterification reaction: Effect of $\mathrm{Fe} / \mathrm{Al}$ ratio on structural and performance. Environ. Sci. Pollut. Res. 2018, 25, 32811-32821. [CrossRef] [PubMed]

55. Rahmani Vahid, B.; Saghatoleslami, N.; Nayebzadeh, H.; Toghiani, J. Effect of alumina loading on the properties and activity of $\mathrm{SO}_{4}{ }^{2-} / \mathrm{ZrO}_{2}$ for biodiesel production: Process optimization via response surface methodology. J. Taiwan Inst. Chem. Eng. 2018, 83, 115-123. [CrossRef]

56. Safakish, E.; Nayebzadeh, H.; Saghatoleslami, N.; Kazemifard, S. Comprehensive assessment of the preparation conditions of a separable magnetic nanocatalyst for biodiesel production from algae. Algal Res. 2020, 49, 101949. [CrossRef]

57. Nayebzadeh, H.; Naderi, F.; Rahmanivahid, B. Assessment the synthesis conditions of separable magnetic spinel nanocatalyst for green fuel production: Optimization of transesterification reaction conditions using response surface methodology. Fuel 2020, 271, 117595. [CrossRef]

58. Nayebzadeh, H.; Saghatoleslami, N.; Haghighi, M.; Tabasizadeh, M.; Binaeian, E. Comparative assessment of the ability of a microwave absorber nanocatalyst in the microwave-assisted biodiesel production process. Comptes Rendus Chim. 2018, 21, 676-683. [CrossRef]

59. Nayebzadeh, H.; Saghatoleslami, N.; Tabasizadeh, M. Application of microwave irradiation for fabrication of sulfated $\mathrm{ZrO}_{2}-$ $\mathrm{Al}_{2} \mathrm{O}_{3}$ nanocomposite via combustion method for esterification reaction: Process condition evaluation. J. Nanostruct. Chem. 2019, 9, 141-152. [CrossRef]

60. Naderi, F.; Nayebzadeh, H. Performance and stability assessment of Mg-Al-Fe nanocatalyst in the transesterification of sunflower oil: Effect of Al/Fe molar ratio. Ind. Crops Prod. 2019, 141, 111814. [CrossRef]

61. Azmoon, A.-H.; Ahmadpour, A.; Nayebzadeh, H.; Saghatoleslami, N.; Heydari, A. Fabrication of nanosized $\mathrm{SO}_{4}{ }^{2-} / \mathrm{Co}_{-\mathrm{Al}}$ mixed oxide via solution combustion method used in esterification reaction: Effect of urea-nitrate ratio on the properties and performance. J. Nanostruct. Chem. 2019, 9, 247-258. [CrossRef]

62. Li, S.; Han, Q.; Jia, X.; Zahid, A.H.; Bi, H. Room-temperature one-step synthesis of tube-like S-scheme BiOBr/BiO (HCOO) Br-x heterojunction with excellent visible-light photocatalytic performance. J. Appl. Surf. Sci. 2020, 530, 147208. [CrossRef]

63. Dou, L.; Jin, X.; Chen, J.; Zhong, J.; Li, J.; Zeng, Y.; Duan, R. One-pot solvothermal fabrication of S-scheme $\mathrm{OVV}^{-}-\mathrm{Bi}_{2} \mathrm{O}_{3} / \mathrm{Bi}_{2} \mathrm{SiO}_{5}$ microsphere heterojunctions with enhanced photocatalytic performance toward decontamination of organic pollutants. J. Appl. Surf. Sci. 2020, 527, 146775. [CrossRef] 
64. Hashemzehi, M.; Pirouzfar, V.; Nayebzadeh, H.; Alihosseini, A. Application of response surface methodology to optimize high active $\mathrm{Cu}-\mathrm{Zn}$-Al mixed metal oxide fabricated via microwave-assisted solution combustion method. Adv. Powder Technol. 2020, 31, 1470-1479. [CrossRef]

65. Rohani, A.; Abbaspour-Fard, M.H.; Abdolahpour, S. Prediction of tractor repair and maintenance costs using Artificial Neural Network. Expert Syst. Appl. 2011, 38, 8999-9007. [CrossRef]

66. Najafi, B.; Akbarian, E.; Lashkarpour, S.M.; Aghbashlo, M.; Ghaziaskar, H.S.; Tabatabaei, M. Modeling of a dual fueled diesel engine operated by a novel fuel containing glycerol triacetate additive and biodiesel using artificial neural network tuned by genetic algorithm to reduce engine emissions. Energy 2019, 168, 1128-1137. [CrossRef]

67. Taki, M.; Abdanan Mehdizadeh, S.; Rohani, A.; Rahnama, M.; Rahmati-Joneidabad, M. Applied machine learning in greenhouse simulation; new application and analysis. Inf. Process. Agric. 2018, 5, 253-268. [CrossRef]

68. Miraei Ashtiani, S.-H.; Rohani, A.; Aghkhani, M.H. Soft computing-based method for estimation of almond kernel mass from its shell features. Sci. Hortic. 2020, 262, 109071. [CrossRef]

69. Zareei, J.; Rohani, A. Optimization and study of performance parameters in an engine fueled with hydrogen. Int. J. Hydrog. Energy 2020, 45, 322-336. [CrossRef]

70. Amini, S.; Taki, M.; Rohani, A. Applied improved RBF neural network model for predicting the broiler output energies. Appl. Soft Comput. 2020, 87, 106006. [CrossRef] 